1 Universidade Federal da Bahia (UFBA), Instituto Multidisciplinar em Saúde (IMS) -Vitória da Conquista (BA), Brasil.

nilia.prado@ufba.br

2 Universidade Federal da Bahia (UFBA), Instituto de Saúde Coletiva (ISC), Programa de PósGraduação em Saúde Coletiva - Salvador (BA) Brasil.

medina@ufba.br

3 Universidade Federal da Bahia (UFBA), Instituto de Saúde Coletiva (ISC), Programa de Pós-

Graduação em Saúde

Coletiva - Salvador (BA)

Brasil.

aquino@ufba.br

\section{Intervenção intersetorial para promoção da saúde em sistemas locais: um estudo de avaliabilidade}

\author{
Intersectoral action for health promotion in local systems: a study of \\ evaluability
}

Nília Maria de Brito Lima Prado', Maria Guadalupe Medina², Rosana Aquino ${ }^{\mathbf{1}}$

RESUMO Trata-se de um estudo de um estudo de avaliabilidade da intervenção intersetorial Promovendo Saúde na Escola (Prose) para a promoção da saúde no âmbito da Estratégia Saúde da Família, desenvolvida em cinco municípios baianos. Seu objetivo foi o de verificar se a intervenção foi bem concebida, elaborar um modelo lógico de intervenção contendo dimensões e critérios para a fase de avaliação e identificar áreas críticas a serem aprimoradas. Os dados derivaram de análise documental e entrevistas com informantes-chave, sendo o modelo lógico submetido à avaliação por técnica de consenso. Os resultados revelaram a necessidade de aprimorar as ações de educação formal e gestão de ações intersetoriais. A intervenção mostrou-se passível de avaliação.

PALAVRAS-CHAVE Promoção da saúde. Saúde escolar. Avaliação em saúde. Colaboração intersetorial.

ABSTRACT This is an evaluability (evaluability assessment) study of Promovendo Saúde na Escola (Prose) intervention intersectoral action to promote health in the context of the Family Health Strategy, developed in five municipalities in the State of Bahia. The study aimed both to verify whether the intervention was well designed and to develop a logical intervention model containing dimensions and criteria as for the evaluation step, as well as for the identification of critical areas in need for improvement. Data were gathered by means of document analysis and interviews with key informants, being the logic model validated by consensus technique. Results revealed the need to improve actions of formal education and intersectoral management. We concluded for the evaluation availability.

KEYWORDS Health promotion. School health. Health evaluation. Intersectoral collaboration. 


\section{Introdução}

A perspectiva de atuação intersetorial tem sido um pressuposto nos discursos oficiais sobre a promoção de saúde e dos Determinantes Sociais da Saúde (DSS) e uma estratégia importante para a efetivação de políticas públicas e reorganização do modelo de atenção em sistemas universais de saúde de diversos países (BRASIL, 2007B; KELEHER, 2007). Uma das iniciativas mais consolidadas no mundo tem sido a articulação dos setores saúde e educação, a exemplo da Iniciativa Global de Saúde nas Escolas, da Iniciativa Regional das Escolas Promotoras de Saúde (Ireps) e da experiência da estratégia de Escolas Promotoras de Saúde (EPS) difundida na América Latina (CASEMIRO; FONSECA; SECCO, 2014).

No Brasil, os programas de saúde escolar têm larga tradição, muito embora, na maioria das vezes, com perspectivas restritas a práticas higienistas, assistencialistas e verticalizadas (FIGUEIREDO; MACHADO; ABREU, 2010), com predomínio de ações curativas por meio de triagem e avaliação clínica e nutricional (MORETTI, 2010; OLIVEIRA ET AL., 2013; TAGLETA ET AL., 2011), i.e., desnutrição e carências nutricionais por hipovitaminose A e anemia ferropriva, saúde bucal, auditiva e oftalmológica, tratamento de doenças parasitárias, transmissíveis e respiratórias, tratamento para a dependência de álcool, drogas e tabaco; ações preventivas intermitentes orientadas para práticas educacionais (PAULETO; PEREIRA; CYRINO, 2004; TAGLIETA ET AL., 011; TODENTI ET AL., 2012) relacionadas à higiene bucal, obesidade infantil, educação sexual; ou ações planejadas com base em campanhas sazonais (CAVALCANTI; LUCENA; LUCENA, 2014).

No âmbito dos sistemas de saúde em decorrência do processo de redemocratização da saúde e da reorientação dos modelos de atenção à saúde, a Atenção Primária à Saúde (APS) passou a ser o lócus preferencial das ações de promoção da saúde, incluindo a discussão acerca da necessidade do estabelecimento de propostas intersetoriais com outros setores e equipamentos sociais do território de abrangência, a fim de viabilizar soluções mais efetivas para os problemas de saúde vivenciados pela população adscrita (MEDINA; HARTZ, 2009).

Mais recentemente, o Programa Saúde na Escola (PSE) propôs o fortalecimento da integração e articulação sustentável entre as políticas de educação básica e de saúde, a partir da atuação nos territórios, privilegiando as necessidades das comunidades locais e demarcando uma nova abordagem para o desenvolvimento de ações e atuação dos profissionais de educação e saúde no espaço escolar. Uma das diretrizes da política de atenção à saúde do escolar no Brasil critica o desenvolvimento de ações pontuais e isoladas e sugere a perspectiva de articulação entre a saúde e a educação que, de maneira crítica, reflexiva e de forma transversal e interdisciplinar, considerem a integralidade dos escolares e as especificidades do território de atuação (BRASIL, 2007A).

Contudo, apesar de o PSE, na condição de estratégia política, trazer em seu bojo um conjunto de princípios e diretrizes que orientam para as práticas pautadas pela integralidade, intersetorialidade, participação social e corresponsabilidade, a articulação com a APS no âmbito local não está consolidada. Nesse sentido, a intervenção intersetorial Promovendo Saúde na Escola (Prose), objeto deste estudo, foi elaborada por meio de um projeto desenvolvido por pesquisadores do Instituto de Saúde Coletiva da Universidade Federal da Bahia e financiado pelo Fundo Nacional de Saúde - Secretaria de Vigilância em Saúde do Ministério da Saúde com o apoio técnico das Secretarias Estaduais de Saúde e Educação do Estado da Bahia. Seus pressupostos foram a necessidade de desenvolver ferramentas e mecanismos que fortalecessem a execução do PSE articulado com a Estratégia Saúde da Família (ESF) nos municípios, que constituem os cenários prioritários para a implementação de políticas, cujas ações fomentem o redirecionamento do modelo de atenção à saúde.

Este artigo apresenta os resultados do estudo de avaliabilidade da intervenção intersetorial Prose, que teve como objetivos elaborar o modelo lógico da intervenção; identificar 
a percepção dos atores sociais quanto a seus objetivos e implantação e identificar áreas críticas a serem melhoradas. Assim, constituíram-se como questões norteadoras deste estudo a adequada definição dos objetivos da intervenção Prose, a percepção dos agentes envolvidos sobre os objetivos, ações e atribuições da intervenção, verificar se a intervenção estava, na ocasião, apta a ser avaliada e se existiam pontos críticos da intervenção a ser melhorados.

\section{Métodos}

Trata-se de estudo de avaliabilidade da intervenção Prose, realizado no período de outubro a novembro de 2013. Os estudos de avaliabilidade (evaluability assessment) consistem no exame sistemático e preliminar de um programa, em sua teoria e em sua prática, a fim de determinar se há justificativa para uma avaliação extensa ou para melhor delimitar os objetivos do programa, bem como identificar áreas críticas a serem priorizadas na avaliação (ROSSI ET AL., 2016; WHOLEY ET AL., 2004). Salienta-se que para que uma intervenção possa ser considerada avaliável, deve ser operada conforme seus pressupostos, possuir estabilidade em longo prazo e antecipar o alcance de resultados parciais, considerados positivos.

\section{Caracterização da intervenção}

A intervenção Prose teve como principal público alvo os estudantes do ensino médio entre 15 e 18 anos, matriculados em escolas públicas da rede estadual de ensino pertencentes a territórios cobertos pela ESF em cinco municípios baianos de médio porte, selecionados por randomização com base em características sócio demográficas que atendiam aos seguintes critérios: população total entre 20.000 e 60.000 habitantes; cobertura da ESF superior a 90\%; PSE implantado em pelo menos duas escolas; e a presença de educador físico e nutricionista do Núcleo de Apoio à Saúde da Família (Nasf).

Ademais, a intervenção objetivou promover práticas de alimentação saudável e atividades físicas dentro e fora da escola; e favorecer o protagonismo dos escolares, o desenvolvimento e gestão de ações intersetoriais por meio de estratégias direcionadas à dinamização e articulação da execução do PSE no território. Com vistas a fomentar a articulação de ações intersetoriais, o Prose contemplou múltiplos componentes, traduzidos por ações em diversos espaços do território de atuação das equipes de saúde e da escola: comunidade e equipamentos sociais, família e redes de apoio social e indivíduos.

Cabe salientar que a etapa inicial da intervenção contou com uma fase preparatória, na qual foram realizadas oficinas com o objetivo de capacitar os professores das escolas participantes por profissionais de saúde que atuavam na ESF e por nutricionistas e educadores físicos do Nasf para a execução de ações articuladas e para constituir novos espaços de diálogo entre os setores da saúde e da educação, direcionando-os para um processo contínuo de planejamento e monitoramento de ações intersetoriais. $\mathrm{O}$ fato de tomar como ponto de partida, o processo pedagógico evidenciava o intuito de reforçar habilidades e competências e, consequentemente, de formar agentes multiplicadores com potencial para compartilhar um problema, como também, ampliar a autonomia local para identificar e planejar ações locais.

\section{Produção de dados}

Inicialmente, realizou-se a análise de todos os documentos produzidos pelo grupo de pesquisa responsável pela elaboração e planejamento da intervenção Prose nos municípios, quais sejam: projeto, relatórios, atas de reunião, áudios e vídeos de aulas e oficinas preparatórias da intervenção. A partir dessa análise, elaborou-se um modelo lógico preliminar da intervenção. Neste, constavam os objetivos, componentes, ações e resultados esperados no longo prazo.

Para aprimorar o modelo lógico, posteriormente, foram realizadas entrevistas semiestruturadas, orientadas por roteiros diferenciados 
por categoria dos 68 informantes-chave, quais sejam: 8 técnicos do projeto, 41 professores, 9 profissionais de saúde, 10 estudantes monitores. As entrevistas foram realizadas pelo pesquisador principal, precedidas da observação dirigida por meio de visitas in loco aos cinco municípios. Obteve-se o consentimento informado por escrito, sendo assegurados aos respondentes o sigilo e a confidencialidade das informações.

As entrevistas foram gravadas e transcritas na íntegra. Em seguida, procedeu-se à análise e classificação dos extratos que continham as ideias centrais fornecidas pelos informantes. O material foi organizado de modo a permitir a identificação de convergências e divergências nos discursos dos entrevistados, sendo realizada a triangulação das fontes de evidência mediante a leitura dos documentos e entrevistas transcritas. Posteriormente, realizou-se uma primeira categorização em unidades de análise com base nos objetivos, ações e componentes da intervenção no processo de implantação, e, por fim, procedeu-se à síntese dos resultados.

O modelo lógico revisado foi submetido à apreciação de pesquisadores integrantes do projeto na qualidade de especialistas na área estudada, aplicando-se a técnica de consenso por Conferência de Consenso, uma técnica mista, adaptação da técnica de grupo nominal e do método Delfos (SOUZA; VIEIRA-DA-SILVA; HARTZ, 2005). A técnica contemplou quatro fases: (1) preenchimento individual de uma matriz; (2) validação individual do modelo lógico; (3) discussão aberta entre os participantes e (4) uma nova resposta individual às questões postas na matriz.

1. Preenchimento individual de uma matriz: inicialmente, enviou-se aos participantes, por meio de correio eletrônico, uma matriz com a descrição dos objetivos, componentes, ações, resultados esperados e público alvo da intervenção. $\mathrm{O}$ respondente foi solicitado a pontuar de 0 a 10 cada item da matriz, traduzindo sua discordância ou concordância em relação ao enunciado. Havia espaço para comentários e sugestões. Após a consolidação das respostas individuais dos participantes, o pesquisador principal reenviou a matriz revisada aos participantes.

2. Validação individual do modelo lógico: a matriz revisada, incluindo indicadores, critérios e padrões de avaliação, foi reenviada aos participantes, por correio eletrônico, assim como o modelo lógico, já em forma de representação esquemática, para uma nova apreciação individual. Nessa fase, solicitou-se que cada participante atribuísse uma nota que variava de zero a dez a cada um dos indicadores, critérios e padrões da matriz revisada.

A partir das respostas, calculou-se a média aritmética e o desvio-padrão para cada critério, indicador e padrão. O desvio-padrão serviu para estimar o grau de consenso. Para inclusão na matriz de julgamento, adotou-se o seguinte procedimento: (1) todo indicador e padrão com média superior a sete foi considerado importante. Abaixo disso, seria considerado pouco importante, não devendo compor a matriz; (2) todo indicador e padrão com desvio padrão inferior a três foi considerado consensual; e (3) o indicador e padrão com média igual ou superior a sete e desvio padrão igual ou superior a três, mesmo quando importantes, não compuseram a matriz, pois não foram consensuais.

3. Discussão aberta entre os participantes: na terceira fase, ocorreu a discussão aberta do modelo lógico com a presença de todos os participantes e procedeu-se à definição de pesos. Na matriz final, a soma de todos os pontos atribuídos totalizou 100 pontos. Esses pontos foram distribuídos entre os critérios, indicadores e padrões selecionados de acordo com sua importância relativa. O componente 'ensino formal' foi o mais valorizado, sendo atribuídos 60 pontos. O componente 'educação e comunicação’ foi o segundo mais valorizado, com 30 pontos; e o componente 'gestão de ações intersetoriais' obteve 10 pontos. Nessa fase, também foram discutidas as 
gradações relativas a cada critério, indicador e padrão, de modo a atribuir o grau de implantação das ações segundo os graus implantação incipiente, implantação intermediária e implantação avançada.

4. Solicitação de nova resposta individual às questões postas na matriz: na quarta fase da
Técnica de Consenso, a matriz de julgamento contendo os pesos atribuídos foi submetida a nova apreciação pelos pesquisadores por meio de correio eletrônico. Após a quarta etapa, atingiu-se a formulação do modelo lógico definitivo da intervenção e da matriz de julgamento com critérios ponderados, indicadores e padrões validados.

Tabela 1. Matriz de critérios e indicadores para a avaliação

\begin{tabular}{|c|c|c|c|c|c|c|c|c|}
\hline \multirow{3}{*}{ 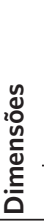 } & \multirow[b]{2}{*}{ Critérios } & \multirow[b]{2}{*}{ Padrão } & \multirow[b]{2}{*}{ Indicador } & \multicolumn{3}{|c|}{ Pontuação } & \multirow[b]{2}{*}{ Peso } & \multirow[b]{2}{*}{$\begin{array}{r}\text { Pontuação } \\
\text { máxima }\end{array}$} \\
\hline & & & & $\begin{array}{r}\text { Incipiente } \\
(\text { INC) }(\leq 29 \\
\text { pontos })\end{array}$ & $\begin{array}{l}\text { Intermediário } \\
\text { (INT) (entre } \\
30 \text { e } 69 \text { pts) }\end{array}$ & $\begin{array}{r}\text { Avançado } \\
(\text { AVA })(\geq 70 \\
\text { pontos }) \\
\end{array}$ & & \\
\hline & \multicolumn{8}{|c|}{ Componente: Ensino Formal } \\
\hline \multirow{2}{*}{ 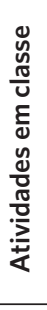 } & \multirow{2}{*}{$\begin{array}{l}\text { Realização de ses- } \\
\text { sões temáticas sobre } \\
\text { alimentação saudável } \\
\text { em atividades curri- } \\
\text { culares obrigatórias. }\end{array}$} & $\begin{array}{l}8 \text { sessões temáticas } \\
\text { com duração de } 50 \\
\text { minutos a cada } 15 \\
\text { dias. }\end{array}$ & $\begin{array}{l}\text { no - de sessões temáticas } \\
\text { conduzidas ou assistidas } \\
\text { em relação ao n.․total } \\
\text { de sessões temáticas } \\
\text { propostas. }\end{array}$ & $<5$ & 5 a 9 & 10 & 1,4 & 14,0 \\
\hline & & $\begin{array}{l}\text { Inclusão de um plano } \\
\text { de aula para cada } \\
\text { sessão temática. }\end{array}$ & $\begin{array}{l}\text { no de planos de aulas in- } \\
\text { cluídos em relação ao n.․․ } \\
\text { total de planos de aulas. }\end{array}$ & $<5$ & 5 a 9 & 10 & 0,6 & 6,0 \\
\hline \multirow{2}{*}{ 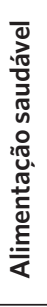 } & $\begin{array}{l}\text { Inclusão do consumo } \\
\text { de alimentos sau- } \\
\text { dáveis no ambiente } \\
\text { escolar. }\end{array}$ & $\begin{array}{l}\text { Consumo de meren- } \\
\text { da escolar contendo } \\
\text { alimentos saudáveis } \\
\text { semanal. }\end{array}$ & $\begin{array}{l}\text { Consumo de alimentos } \\
\text { saudáveis na escola três } \\
\text { vezes por semana. }\end{array}$ & 0 & 1 a 9 & 10 & 0,5 & 5,0 \\
\hline & $\begin{array}{l}\text { Inclusão do consumo } \\
\text { de alimentos saudá- } \\
\text { veis no domicilio. }\end{array}$ & $\begin{array}{l}\text { Consumo de alimentos } \\
\text { saudáveis domicílio } \\
\text { três vezes por semana. }\end{array}$ & $\begin{array}{l}\text { Inclusão do consumo de } \\
\text { alimentos saudáveis em } \\
\text { domicílio dos escolares } \\
\text { por semana. }\end{array}$ & 0 & 1 a 2 & 3 a 5 & 1,0 & 5,0 \\
\hline \multirow{5}{*}{ 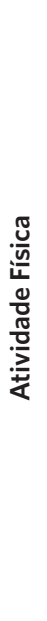 } & \multirow{2}{*}{$\begin{array}{l}\text { Atividade física cur- } \\
\text { ricular no turno das } \\
\text { atividades curricula- } \\
\text { res obrigatórias. }\end{array}$} & $\begin{array}{l}\geq 80 \text { minutos sema- } \\
\text { nais. }\end{array}$ & $\begin{array}{l}\text { Duração da atividade físi- } \\
\text { ca curricular por semana. }\end{array}$ & 0 & 1 a 2 & 3 a 5 & 1,0 & 5,0 \\
\hline & & $\geq 5$ h por semana. & $\begin{array}{l}\text { Frequência das atividades } \\
\text { curriculares de educação } \\
\text { física por semana. }\end{array}$ & 0 & 1 a 2 & 3 a 5 & 1,0 & 5,0 \\
\hline & $\begin{array}{l}\text { Implantação de } \\
\text { programa esportivo } \\
\text { curricular no turno } \\
\text { oposto das aulas. }\end{array}$ & $\begin{array}{l}2 \text { horas semanais no } \\
\text { turno oposto às aulas } \\
\text { obrigatórias. }\end{array}$ & $\begin{array}{l}\text { Carga horária de atividade } \\
\text { física no turno oposto as } \\
\text { aulas por semana. }\end{array}$ & 0 & 1 a 2 & 3 a 5 & 1,0 & 5,0 \\
\hline & \multirow{2}{*}{$\begin{array}{l}\text { Sessão temática } \\
\text { sobre atividade física } \\
\text { em atividades curricu- } \\
\text { lares obrigatórias. }\end{array}$} & $\begin{array}{l}1 \text { sessão temática com } \\
\text { duração de } 50 \text { min a } \\
\text { cada } 15 \text { dias. }\end{array}$ & $\begin{array}{l}\text { Sessão temática porposta } \\
\text { pelo projeto Prose condu- } \\
\text { zida ou assistida. }\end{array}$ & 0 & 1 & 1 a 2 & 2,5 & 5,0 \\
\hline & & $\begin{array}{l}\text { Inclusão de plano de } \\
\text { aula para a sessão } \\
\text { temática sobre ativida- } \\
\text { de física. }\end{array}$ & $\begin{array}{l}\text { Inclusão de plano de aula } \\
\text { da sessão temática sobre } \\
\text { atividade física. }\end{array}$ & 0 & 1 & 1 a 2 & 2,5 & 5,0 \\
\hline
\end{tabular}


Tabela 1. (cont.)

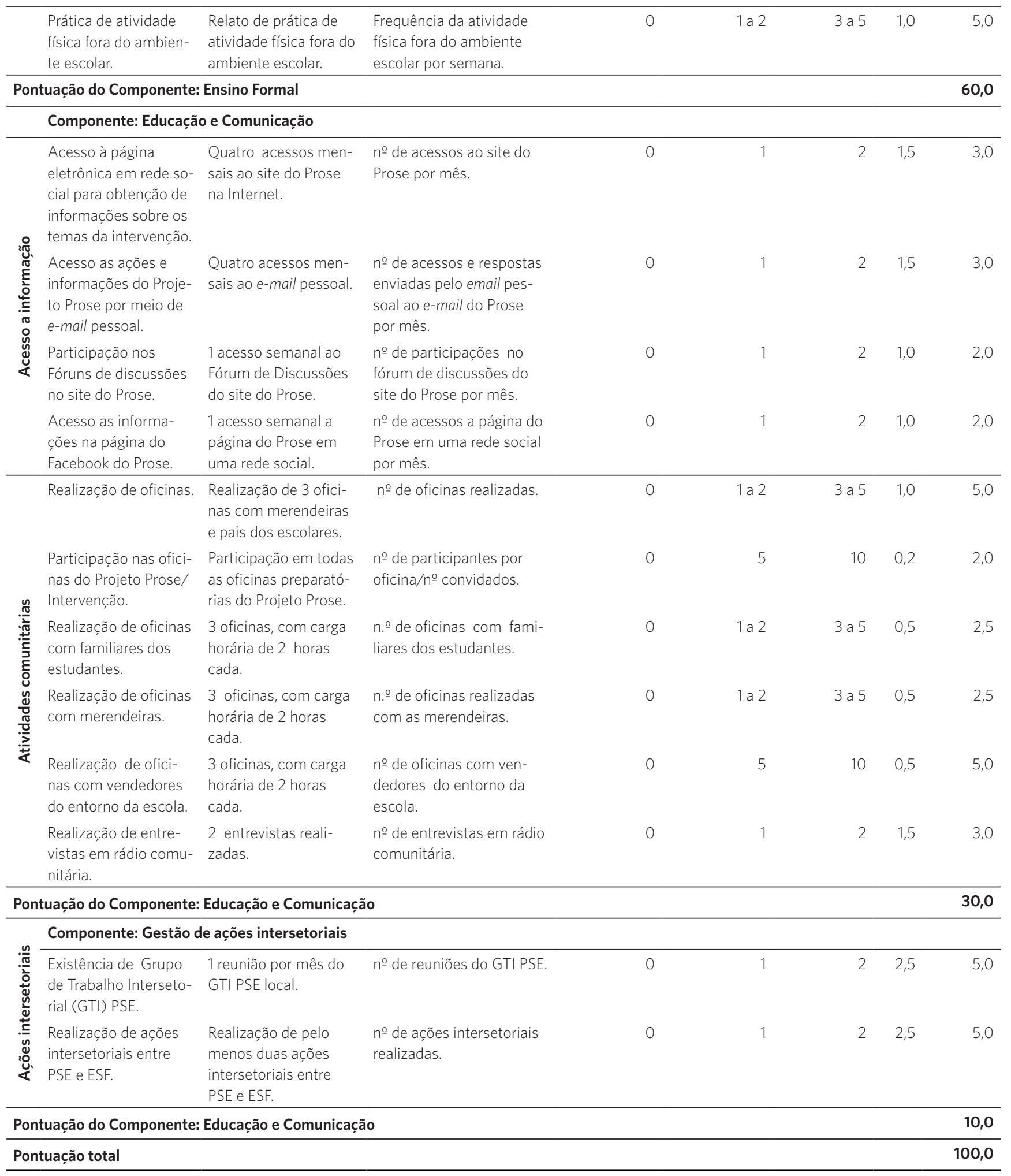

Fonte: Elaboração própria. 
O projeto de pesquisa foi aprovado pelo Comitê de Ética do Instituto de Saúde Coletiva da Universidade Federal da Bahia (CCAE 09709112.3.0000.5030) pelo parecer 182.685, de 4 de janeiro de 2013. Em conformidade com a Resolução nº466/2012 do Conselho Nacional de Saúde, assegurou-se o anonimato dos participantes, sigilo e confidencialidade das informações coletadas.

\section{Resultados e discussão}

\section{Modelo lógico da intervenção Prose}

Após a validação do modelo lógico definitivo (tabela 1), a intervenção Prose pôde ser descrita por meio de modelo lógico. Nele constam os objetivos da intervenção, quais sejam, as de promover a alimentação saudável na escola; incentivar a Atividade Física (AF) dentro e fora do âmbito escolar; e favorecer o protagonismo dos escolares e o desenvolvimento de ações intersetoriais para promoção da saúde. Para cumprir tais objetivos, foram desenhados três componentes: O componente ensino formal, mais voltado para a formação dos alunos, articulado com os próprios objetivos pedagógicos das escolas participantes nos municípios. O componente 'educação e comunicação', que estava direcionado à difusão conhecimentos por meio do desenvolvimento de estratégias, dentro e fora do contexto escolar. E o componente 'gestão de ações intersetoriais', criado como sustentação para a implantação dos demais.

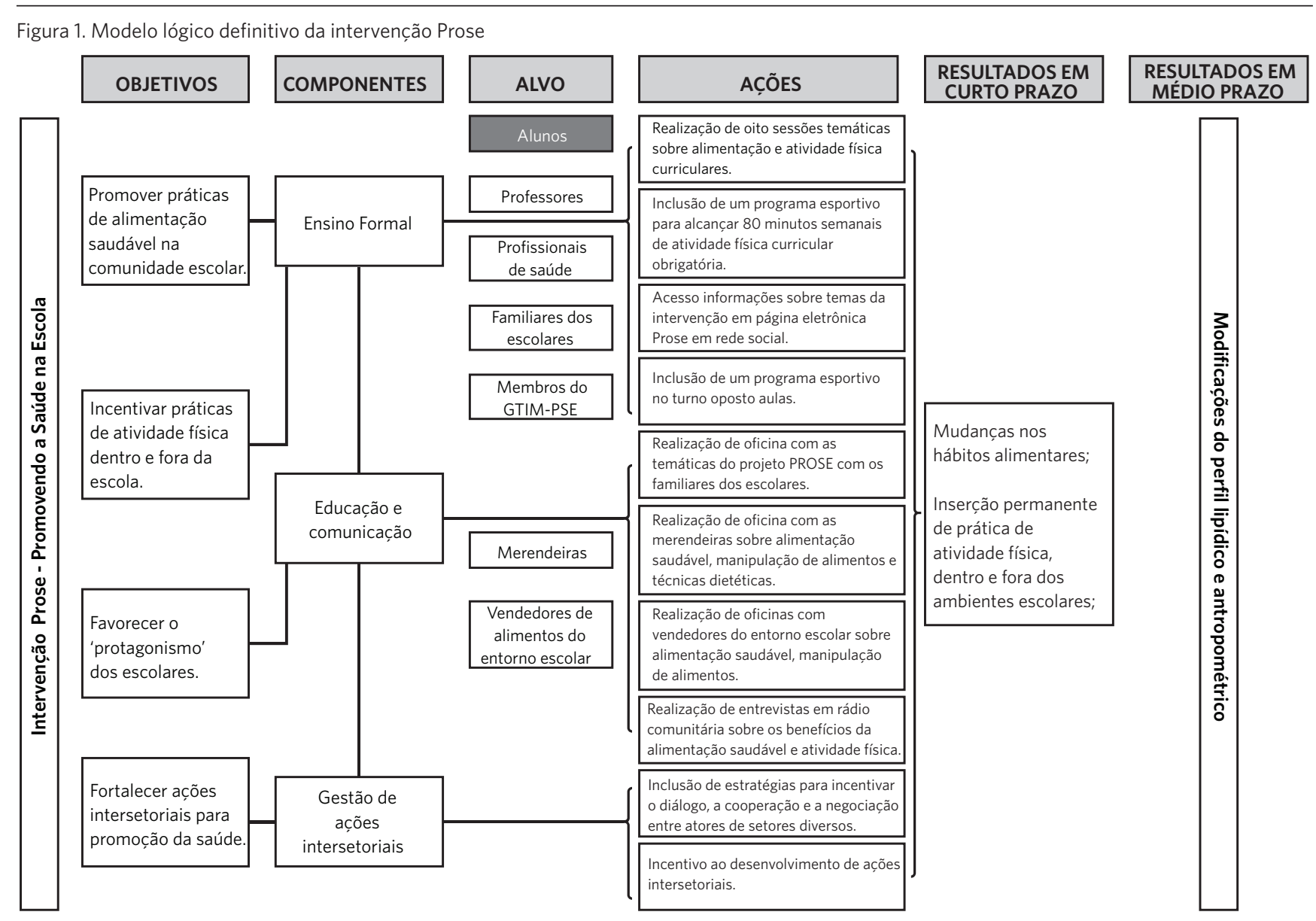

Fonte: Elaboração própria. 
O componente ensino formal constou de oito sessões temáticas para promoção da saúde na escola; alimentação saudável; atividade física e saúde; gorduras, sal e açúcar; avaliação nutricional; uso de suplementos; rotulagem de alimentos; alimentos funcionais. As sessões foram inseridas em atividades curriculares obrigatórias nas escolas por meio de um programa disponibilizado pelos pesquisadores que contemplava materiais didáticos impressos, vídeos didáticos, manual com a descrição dos planos de aula e orientações para a implantação das sessões temáticas, que poderiam ser ministradas por professores e profissionais de saúde. Esse componente objetivou, também, inserir na disciplina de educação física um programa para ampliar para 80 minutos semanais a carga horária dedicada à realização de atividades físicas curriculares obrigatórias, especialmente por meio de práticas desportivas.

O componente 'educação e comunicação' contemplou a difusão de informações em sites eletrônicos, redes sociais, entrevistas em rádio comunitária ou jornais veiculados por transmissão televisiva sobre os benefícios para a saúde derivados da inclusão da alimentação saudável e da prática regular de atividades físicas, assim como, incentivou a realização de atividades que promovessem o protagonismo dos adolescentes para fomentar a mudança dos hábitos cotidianos. Com o propósito de alcançar a comunidade externa, inclusive as famílias dos adolescentes, realizaram-se oficinas com familiares dos estudantes, merendeiras e vendedores ambulantes de alimentos no entorno das escolas sobre alimentação saudável, boas práticas de manipulação de alimentos e técnicas dietéticas.

O componente 'gestão de ações intersetoriais' constituiu estratégias para incentivar o incremento de habilidades e valores que favorecessem o diálogo, a cooperação e negociação e a construção de viabilidade para implantar ações articuladas. Dentre os métodos adotados, destacam-se a construção de plano de ação local e a constituição e formalização de Grupo de Trabalho Intersetorial (GTI), composto por técnicos e gestores da saúde, da educação e da sociedade civil, com o intuito de planejar, desenvolver, acompanhar e avaliar as atividades direcionadas à promoção da saúde no contexto escolar.

Em síntese, almejou-se como resultados de curto prazo a mudança de hábitos alimentares e a inserção contínua da prática de atividade física na escola no turno de aula e no turno oposto, bem como fora da escola, e o incentivo a hábitos alimentares saudáveis na merenda escolar e em domicílio. No longo prazo, o objetivo é a diminuição do perfil lipídico, calculado pelas concentrações séricas de colesterol LDL e pelas medidas antropométricas dos escolares, aproximando-as dos escores considerados ideais.

\section{Identificação de clareza entre os atores sociais quanto aos objetivos e atribuições para implantação da intervenção Prose}

O estudo de avaliabilidade aqui relatado objetivou, do mesmo modo, identificar se a intervenção estava, de fato, sendo implantada nos diversos locais. Nesse sentido, foi possível confirmar que os objetivos da intervenção estavam claramente definidos nos documentos do projeto Prose. Observou-se que os objetivos descritos no projeto de intervenção, coincidiram com as formulações dos diferentes atores, quais sejam, pesquisadores do projeto, professores, profissionais de saúde e estudantes monitores. O único objetivo que divergiu desse consenso foi aquele relacionado ao protagonismo dos escolares.

A ausência de clareza quanto ao protagonismo revelou-se uma das áreas críticas da intervenção. Esse fato pode ter ocorrido por motivos relacionados ao desenho da intervenção e à incipiente qualificação técnica prévia dos atores envolvidos.

Do ponto de vista dos atores, percebeu-se 
um descompasso. Os alunos monitores não se viram como protagonistas na atribuição de multiplicadores das ações da intervenção. Justificaram a ausência de orientações necessárias para o exercício do protagonismo que pudessem subsidiar a articulação com os demais escolares e viabilizar a multiplicação das informações apreendidas e necessárias para o desenvolvimento e extrapolação das ações intersetoriais a outros domínios do território, inclusive ao contexto familiar.

[...] Fui escolhido pelo diretor, dirigente e administrador da instituição escolar, para participar do projeto. Depois lembro que teve uma aula do projeto Prose, com os pesquisadores, que explicou o projeto e falava como melhorar a merenda e esportes, educação física. Vários colegas meus participaram. Depois falaram que nós iríamos ajudar nessas aulas e a fazer algumas atividades com os professores na escola e nas ruas do bairro. Mas, não entendi bem como seria... nunca fizemos isso, não é? É diferente de ser líder de classe. (E22-aluno).

Os professores questionaram que, apesar de essa atribuição ter sido discutida com os pesquisadores e escolares nas oficinas de capacitação da fase preparatória, a operacionalização da função não foi bem definida. Dessa forma, não se sentiram aptos a assumir a responsabilidade de agregar estratégias que viabilizassem o protagonismo dos escolares. Os profissionais de saúde ressaltaram, da mesma forma, que não possuíam competência técnica necessária para estimular o protagonismo dos escolares para o desenvolvimento de ações direcionadas à promoção da saúde.

[...] foram escolhidos pelos pesquisadores do Prose e pelo diretor, alguns alunos para assumir uma função de monitor e nos auxiliar a desenvolver as atividades para promover alimentação saudável e atividade física na escola e no bairro. Eram os alunos que já tinham a função de líder da sala. Mas, na prática, não sabíamos como eles deveriam agir ou se envolver. Confesso que não estamos acostumados a envolver os alunos no planejamento das atividades, eles só costumam participar das aulas, não é? No máximo, desenvolvem feiras de saúde; mas nós planejamos e orientamos tudo [...]. (E10-professor).

Não ficaram claras, na prática, as atribuições de alunos com a função de multiplicador. Lembro que chegamos a discutir na oficina com os alunos, mas não discutimos com os pesquisadores e com professores como desenvolver esta ação. Não cabe a nós formar uma nova competência destes alunos, não é? Nós dominamos apenas o conteúdo da saúde; são os professores que se envolvem com a formação de competências, e acho que esta faz parte do processo educacional. (E28-profissional de saúde).

No que concerne ao desenho da intervenção, do mesmo modo, os pesquisadores expuseram que, apesar dessa atribuição ter sido descrita nos documentos relacionados ao projeto de intervenção, não foram disponibilizados procedimentos operacionais e não houve a discussão de um plano de ação específico com os demais atores envolvidos. Ou seja, os próprios pesquisadores 'dão pistas' de que esse objetivo apresentou fragilidades quanto à constituição de elementos operacionais.

[...] estava previsto pelo projeto de intervenção que alguns alunos com o perfil de liderança fossem selecionados como alunos monitores. Eles teriam a função de multiplicar algumas informacões e incentivar os demais alunos a desenvolver atividades de promoção da saúde, dentro e fora da escola. Mas não sei se essa função ficou tão clara nos documentos disponibilizados para os atores envolvidos e nas oficinas preparatórias... (E11-pesquisador do projeto).

Em relação ao aludido, alguns estudos têm enfatizado a necessidade de reforço de habilidades e competências que subsidiem a identificação e diagnóstico dos reais 
problemas passíveis de uma intervenção, assim como o planejamento e o desenvolvimento de ações para promoção da saúde no contexto escolar como instrumento para o fomento ao protagonismo juvenil e ampliação da capacidade de equanimidade dos setores envolvidos nas decisões de cunho intersetorial (SILVA, 2010).

\section{Monitoramento da implantação da intervenção Prose}

Outro objetivo do estudo foi o de verificar se a intervenção Prose estava, de fato, sendo implantada nas escolas. Alguns agentes entrevistados, i.e., diretores das escolas, professores, alunos e profissionais de saúde confirmaram que a intervenção Prose estava sendo desenvolvida em todas as escolas dos cinco municípios. Os entrevistados relataram o desenvolvimento do componente ensino formal, especialmente as ações relacionadas às videoaulas temáticas, à alimentação escolar e à prática de atividades físicas curriculares obrigatórias.

O Prose foi um o projeto que buscou articular os setores saúde e educação por meio do reforço e incentivo ao desenvolvimento de atividades nas escolas e no território. Permitiu-nos refletir sobre como as ações devem ser planejadas e executadas com os profissionais da Atenção Básica. Conseguimos, ainda no primeiro ano, planejar e dividir as aulas entre os professores e profissionais de saúde. Quase todas já foram dadas. (E15-diretor de escola).

Quanto às aulas, os profissionais de saúde expuseram que as temáticas propostas pela intervenção foram incluídas no cronograma dos componentes curriculares obrigatórios e conduzidas por alguns professores e profissionais de saúde do Nasf. Os escolares confirmaram a exposição e discussão dos conteúdos das videoaulas e a utilização dos materiais didáticos de apoio disponibilizados pelos pesquisadores do Prose.
Eu assisti a cinco aulas; a mais interessante foi a que falava sobre alimentação saudável, pois, depois do vídeo, discutimos e construímos algumas pirâmides alimentares e tivemos a ideia de expor todas em uma feira de ciências! (E25-aluno).

Contudo, no decorrer das práticas educativas, os profissionais de saúde e os professores revelaram dissonâncias quanto à linguagem científica das videoaulas, especialmente no que se refere às distintas matrizes disciplinares e discursivas entre os setores. Para os professores, as temáticas abordadas versavam sobre assuntos mais condizentes com a área da saúde, e que, de certa forma, favoreciam as abordagens dos profissionais da saúde. Por outro lado, os profissionais de saúde alegaram que, apesar de maior domínio quanto às questões propostas pelo Prose, não possuíam competência técnica para o desenvolvimento das aulas, pois requeriam o subsídio de metodologias pedagógicas. Essas contradições, segundo os diretores das escolas, podem ter conduzido a posicionamentos polarizados e à condução isolada das aulas, ora pelos professores ora pelos profissionais de saúde, constituindo-se em entrave para a implantação da intervenção conforme concebida.

Então, o projeto Prose, ao propor que nós, educadores, trabalhássemos o conceito e a prática de promoção da saúde, e como está relacionado com a qualidade de vida, com atividade física e alimentação, não previu a nossa dificuldade em ministrar essas aulas e em discutir esses assuntos dentro das aulas curriculares obrigatórias. Acho que essas aulas deveriam ser conduzidas pelos profissionais de saúde ou que nós tivéssemos mais capacitação nesses assuntos, sobre as ações de saúde, para que pudéssemos despertar mais o interesse dos alunos. (E2-professsor).

A intervenção, apesar de complexa, tem permitido repensarmos a necessidade de inclusão de práticas pedagógicas nos ambientes escolares, mais voltadas para discussões sobre a saúde. 
Não apenas em palestras e aulas, mas de uma forma que envolva, além dos alunos, os pais e familiares. Para os professores, é mais fácil, pois, como eles dominam as metodologias de ensino, então podem repensar como trabalhar essas questões de forma mais envolvente para fixar a atenção e também despertar o interesse contínuo dos alunos. (E3-profissional de saúde).

Tais posicionamentos alertam para a necessidade de se estabelecer, em paralelo à adesão a políticas intersetoriais, a qualificação dos agentes, de modo a assegurar a capacidade operacional na provisão e regulação de ações articuladas com vistas à promoção da saúde no contexto escolar, no âmbito local. Tendo em vista que, o dilema passa a ser operar uma política necessariamente intersetorial explicitada num ambiente com atores que priorizam agendas setoriais previamente definidas. Nesse sentido, a formação dos profissionais de saúde deve contemplar o desenvolvimento de competências e habilidades voltadas para o diálogo e à negociação com os demais atores setoriais e extras setoriais, bem como para a atuação didático-pedagógica no desenvolvimento de ações de educação e promoção da saúde.

Do mesmo modo, a Política Nacional de Educação Permanente no Sistema Único de Saúde (SUS) destaca a necessidade de qualificação dos profissionais na etapa inicial de implantação de uma política intersetorial por meio de capacitações gradativas para viabilizar a adaptação a mudanças e a superação de práticas setorizadas e fragmentadas (KOPTCKE; CAIXETA; ROCHA, 2015; SILVA; TAVARES, 2016). Portanto, a qualificação dos atores de distintos setores tem sido considerada uma estratégia imprescindível à viabilização da interdisciplinaridade e da integralidade da atenção e, consequentemente, da construção de decisões articuladas de modo intra e intersetorial, direcionadas ao enfrentamento dos problemas e situações identificadas nos territórios de atuação dos profissionais.

Em relação ao objetivo de ampliar da carga horária e diversificar as atividades físicas obrigatórias, os escolares e diretores revelaram que os professores de educação física demonstraram empenho, relatando a utilização de materiais didáticos alternativos, tais como cones, cordas, dentre outros, e práticas esportivas como futebol de salão, voleibol, basquete, handebol. Por outro lado, apesar da inclusão das estratégias mencionadas, alguns professores referiram certa dificuldade em implantar novas atividades devido às condições estruturais inadequadas das quadras poliesportivas em determinadas escolas.

No que se refere à ampliação da carga horária no turno oposto e fora do ambiente escolar, os professores indicaram que a participação dos educadores físicos do Nasf, no planejamento e realização das atividades direcionadas aos escolares, i.e., práticas esportivas com participação em torneios esportivos municipais e regionais, e a outros agentes do território - comunidade local e familiares dos escolares - permitiram a ampliação e concretização das ações previstas pela intervenção Prose.

No que diz respeito à alimentação escolar, observou-se convergência e consenso entre os agentes, especialmente quanto à alteração dos cardápios e inclusão de alimentos mais saudáveis, como frutas e verduras na alimentação escolar. Os diretores das escolas ressaltaram que o envolvimento das nutricionistas do Nasf em reuniões mensais para planejamento de compras, definição dos cardápios e orientação das merendeiras viabilizou o preparo de alimentação escolar mais saudável. Os professores e os alunos referiram que introduziram a discussão sobre a temática em feiras de ciências.

[...] o Prose, para mim, é o elo entre a saúde e a Educação. Estávamos precisando desse estímulo para que a coisa acontecesse. As atividades físicas estão sendo desenvolvidas pelos professores e também pela saúde (profissionais do Nasf). E tem envolvido a comunidade externa, do território da escola. (Entrevistado 17-profissional de 
saúde do Nasf).

O projeto tem ajudado a modificar algumas aulas, inclusive de educação física, na escola; acho que é um dos objetivos não só melhorar a quantidade, mas tudo. A merenda da escola mudou. Agora estão servindo mais frutas. Os professores estão falando muito sobre esportes e sobre alguns alimentos. Os profissionais de saúde, nutricionistas, também estão vindo ministrar aulas. (E8-aluno multiplicador).

Percebe-se que a participação dos nutricionistas e educadores físicos do Nasf foi crucial para o desenvolvimento da intervenção Prose ao atuarem como articuladores entre as equipes da ESF e os professores. $\mathrm{O}$ processo de trabalho das equipes do Nasf apoia-se nas diretrizes do apoio matricial, viabilizando o planejamento das ações voltadas para a promoção de práticas de alimentação saudável e atividade física no contexto escolar e de acordo com a necessidade de cada território. De fato, alguns estudos revelaram que o Nasf se configura em uma das estratégias mais promissoras, para superar e auxiliar na conversão de um modelo fragmentado e descontínuo em uma atenção integral a partir da APS, pelo fato de possibilitar a ampliação da articulação entre os atores, e destes com diversos setores, por meio de trabalho compartilhado e da cogestão das ações (KOPTCKE; CAIXETA; ROCHA, 2015).

No que tange aos componentes 'educação e comunicação' e 'gestão de ações intersetoriais', os entrevistados alegaram que o primeiro estava sendo implantado sem contratempos, mas justificaram que o segundo exigia maior esforço dos envolvidos, revelando dificuldades no decorrer do desenvolvimento. Os diretores, professores e profissionais de saúde reconheceram a existência de limitações quanto às capacidades, competências e habilidades técnicas e administrativas, sobretudo as relacionadas ao planejamento de ações integradas entre atores de setores distintos.

As controvérsias, segundo os professores e profissionais de saúde, estavam relacionadas à dificuldade de se estabelecer parceria entre os dois setores para fomentar a implementação de intervenções por meio da identificação de demandas prioritárias ante a predominância de práticas setoriais e a inviabilidade técnica, administrativa e política dos contextos municipais. Para os agentes mencionados, tais fatores conduziram a interações intermitentes e restritas às reuniões esporádicas dos GTIs locais.

[...] o GTI-M PSE existe, e alguns profissionais de saúde e diretores ou professores de escolas também participam, mas, apesar das reuniões frequentes, não sabemos como executar, na prática, as ações articuladas. (E4-comunidade escolar).

[...] existe um GTI-M do PSE e meu nome está lá na portaria que o instituiu. Mas, acho que devemos ter discussões mais próximas do território em que trabalhamos, mas não sei como fazer isso. Em minha opinião, teríamos que ter uma formação específica que nos qualificasse para discutir essas necessidades em cada local e depois de forma mais ampla, no GTI-M, pois, assim, poderíamos traçar as atribuições dos envolvidos, na prática, não é? (E7-profissional da saúde).

Além disso, diversos os aspectos restritivos ao desenvolvimento de ações intersetoriais ressaltados por este estudo, também foram identificados por outros estudos recentes, destacando-se: a dificuldade em conciliar os tempos institucionais dos vários setores; a inexistência de protocolos que norteiem o desenvolvimento das ações integradas; os conflitos decorrentes de disputas políticas e de poder; a preponderância de práticas setoriais centradas em estruturas discursivas e disciplinares próprias e resistentes a novos arranjos intersetoriais; e a necessidade de qualificação dos agentes para que a abordagem intersetorial pudesse ser formalizada como mecanismo de gestão (ALMEIDA, 2013; AZEVEDO; PELICIONE; WESTPHAL, 2012). 


\section{Considerações finais}

O estudo de avaliabilidade da intervenção Prose atingiu o seu objetivo no sentido de confirmar que a intervenção estava implantada na prática nos diferentes locais e de identificar os aspectos e componentes que necessitavam ser aprimorados e priorizados em avaliações posteriores.

Diante dos achados, puderam ser formuladas as seguintes considerações:

1. Necessidade de fortalecimento do componente educação formal, especialmente quanto ao reforço ao processo de autonomia dos alunos monitores com vistas ao desenvolvimento contínuo de multiplicação de ações de promoção da saúde nas escolas e no território.

2. Necessidade de ampliação das ações intersetoriais articuladas por meio do fortalecimento da qualificação e das práticas dos

\section{Referências}

ALMEIDA, F. A. Práticas intersetoriais do programa

de saúde na escola: um estudo sobre as ações e interações dos atores sociais envolvidos. 2013. $220 \mathrm{f}$ Dissertação (Mestrado em Gestão Social, Educação e Desenvolvimento Local) - Centro Universitário UNA, Belo Horizonte, 2013.

AZEVEDO, E.; PELICIONE, M. C. F.; WESTPHAL, M.

F. Práticas intersetoriais nas políticas públicas de promoção da saúde. Physis: Revista de Saúde Coletiva, Rio de Janeiro, v. 22, n. 4, p. 1333-1356, 2012.

BRASIL. Decreto n. 6.286, de 5 de dezembro de 2007. Institui o Programa Saúde na Escola (PSE), e dá outras agentes para que viabilizem a execução e continuidade das ações previstas pelo componente 'gestão de ações intersetoriais'.

Por fim, conclui-se que se trata de intervenção passível de avaliação, na medida em que foi possível caracterizar os seus componentes e ações, oferecendo subsídios para compreensão dos processos implicados em sua operacionalização. Ante tal resultado, foi possível constatar que o momento é bastante oportuno à uma subsequente avaliação, dada a fase de implantação da intervenção Prose.

\section{Colaboradores}

NMBLP trabalhou na concepção, delineamento, coleta, análise e processamento dos dados e redação do artigo, RA trabalhou na revisão crítica e aprovação da versão a ser publicada e MGM trabalhou na concepção, delineamento e revisão crítica da versão final. providências. Diário Oficial [da] República Federativa do Brasil, Brasília, DF, 5 dez. 2007a. Disponível em: < http:// www.planalto.gov.br/ccivil_03/_ato2007-2010/2007/decreto/d6286.htm>. Acesso em: 24 ago. 2017.

Ministério da Saúde. Escolas promotoras de saúde: experiências do Brasil. Ministério da Saúde, Organização Pan-Americana da Saúde. Brasília, DF: Ministério da Saúde, 2007b.

CAMPOS, H. M.; SCHALL, V. T.; NOGUEIRA, M. J. Saúde sexual e reprodutiva de adolescentes: interlocuções com a Pesquisa Nacional de Saúde do Escolar (PeNSE). Saúde em Debate, Rio de Janeiro, v. 37, n. 97, p. 
336-346, abr./jun. 2013.

CASEMIRO, J. P.; FONSECA, A. B. C.; SECCO, F. V. M.

Promover saúde na escola: reflexões a partir de uma revisão sobre saúde escolar na América Latina. Ciência \&t Saúde Coletiva, Rio de Janeiro, v. 19, n. 3, p. 829-840, 2014.

\section{CAVALCANTI, P. B.; LUCENA, C. M. F., LUCENA,}

P. L. C. Programa Saúde na Escola: interpelações

sobre ações de educação e saúde no Brasil. Textos \& Contextos, Porto Alegre, v. 14, n. 2, p. 387-402, 2015.

DIAS, M. A. S. et al. Programa Saúde na Escola: tecendo uma análise nos documentos oficiais. SANARE, Sobral, v. 13, n. 1, p. 29-34, 2014.

FIGUEIREDO, T. A. M.; MACHADO, V. L. T, ABREU,

M. M. S. A saúde na escola: um breve resgate histórico. Ciência \&t Saúde Coletiva, Rio de Janeiro, v. 15, n. 2, p. 397-402, 2010.

KELEHER, H. Health promotion planning and the social determinants of health. In: KELEHER, H.; MACDOUGALL, C.; MURPHY, B. (Ed.). Understanding health promotion. Melbourne: Oxford University Press. 2007. p. 1-21.

KOPTCKE, L. S.; CAIXETA, I. A.; ROCHA, F. G. O olhar de cada um: elementos sobre a construção cotidiana do Programa Saúde na Escola no DF. Tempus actas de saúde coletiva, Brasília, DF, v.9, n. 3, p. 213-232.2015

MEDINA, M. G., HARTZ, Z. M. A. The role of the Family Health Program in the organization of primary care in municipal health systems. Cadernos de Saúde Pública, Rio de Janeiro, v. 25, n. 5, p.1153-67, 2009.

MORETTI A, C. Intersetorialidade nas ações de promoção de saúde realizadas pelas equipes de saúde bucal de Curitiba (PR). Ciência \&t Saúde Coletiva, Rio de Janeiro, v. 15, n. supl. 1, p. 1827-1834, 2010.

OLIVEIRA, R. S. et al. Avaliação da acuidade visual em escolares no município de Herval d'Oeste, Santa Catarina, Brasil. Revista Bras Med Fam Comunidade, Rio de Janeiro, v. 8, n. 28, p. 180-186, 2013.
PAULETO, A. R. C.; PEREIRA, M. L. T.; CYRINO, E. G. Saúde bucal: uma revisão crítica sobre programações educativas para escolares. Ciência \&t Saúde Coletiva, Rio de Janeiro, v. 9, n. 1, p. 121-130, 2004.

ROSSI, S. P. H. et al. Evaluation: A Systematic Approach. SeventhEdition, 2016.

SILVA, D. A. J.; TAVARE S, M. F. L. Ação intersetorial: potencialidades e dificuldades do trabalho em equipes da Estratégia Saúde da Família na cidade do Rio de Janeiro. Saúde em Debate, Rio de Janeiro, v. 40, n. 111, p. 193-205, 2016

SILVA, M. A. I.; MELLO, D. F.; CARLOS, D. M. O adolescente enquanto protagonista em atividades de educação em saúde no espaço escolar. Rev. Eletr. Enf., v. 12, n. 2, p. 287-93, 2010. Disponível em: <https://www.fen. ufg.br/fen_revista/v12/n2/pdf/v12n2a09.pdf>. Acesso em: 24 ago. 2017.

SOUZA, L. E. P. F., VIEIRA-DA-SILVA, L. M.; HARTZ, Z. M. A. Conferência de consenso sobre a imagem-objetivo da descentralização da atenção à saúde no Brasil In: HARTZ, Z. M. A.; VIEIRA-DA-SILVA, L. M. (Org.). Avaliação em Saúde: dos modelos teóricos à prática de avaliação de programas e Sistemas de saúde. Salvador: EDUFBA, 2005. p. 65-102.

TAGLIETA, M. F. A. et al. Impacto de um programa de promoção de saúde escolar sobre a redução da prevalência da cárie em crianças pré-escolares de Piracicaba - SP. RFO UPF, Passo Fundo, v. 16, n. 1, 2011.

TODENTI, P. F.et al. Obesidade: estratégias de prevenção da saúde em ambiente escolar. Cinergis, Santa Cruz do Sul, v. 13, n. 3, p. 1-8, 2012.

WHOLEY, J. S. et al. Handbook of practical program evaluation. Cambridge: Second Edition, 2004.

Recebido para publicação em abril de 2017

Versão final em julho de 2017

Conflito de interesses: inexistente

Suporte financeiro: Fundo Nacional de Saúde/Secretaria de Vigilância em Saúde - Ministério da Saúde, processo no 23066.065458/10-36 